\title{
Teachers' Pedagogical Content Knowledge and the Teaching of Statistics in Secondary Schools in Wakiso District in Uganda
}

\author{
Marjorie S. K. Batiibwe \\ Department of Science, Technical and Vocational Education, School of Education, College of Education and \\ External Studies, Makerere University. P. O. Box 7062, Kampala, Uganda
}

The research was privately financed by the researcher

\section{Abstract}

Statistics is one of the most dynamic, rapidly growing and highly pertinent disciplines today and therefore, this study investigated teachers' pedagogical content knowledge (PCK) and the teaching of statistics in secondary schools in Wakiso District in Uganda. PCK was contextualized as teachers' general knowledge, pedagogical knowledge (PK) and content knowledge (CK). The sample of the study consisted of 60 secondary school mathematics (statistics) teachers. Data sources were the self-administered questionnaire, document analysis (schemes of work and lesson plans), classroom observations and post-lesson interviews. While quantitative data were analyzed using descriptive statistics and Pearson's Linear Correlation Coefficients, qualitative data were analyzed using categorization and narratives. The findings of this study showed that there was no relationship between the teachers' PCK and the teaching of statistics. Mathematics teachers teach statistics theoretically and the implication for practice is that a lot of training has to equip them with statistical knowledge. It was recommended that Ministry of Education and Sports (MoES), Uganda National Examinations Board (UNEB), National Curriculum Development Centre (NCDC), teachers and researchers collaborate together to uplift the standards of teaching of statistics in the country.

Keywords: Pedagogical Content Knowledge, Statistics, Teaching, Uganda

DOI: $10.7176 / \mathrm{JEP} / 10-25-10$

Publication date:September $30^{\text {th }} 2019$

\section{Introduction}

Statistics is one of the most dynamic, rapidly growing and highly pertinent disciplines today. The knowledge of statistics provides a description of a summary of the past, the present and an approximation of the future for, say, an institution. In Uganda, statistics forms part of the mathematics course in the majority of schools at all age levels, ranging from primary to tertiary levels. At primary level, mathematics is taken as a single subject and at the lower secondary level it is taken as two separate options namely Mathematics 456 and Mathematics 475 . Statistics then stands as a subject in its own right at the advanced secondary and tertiary levels. Whereas the Uganda National Examinations Board (UNEB) syllabus (UNEB, 2005, p.106) argues that at ordinary level ("O" level), "mathematics should be visualized as a vehicle for aiding a student to think, reason and articulate logically", statistics does not stand out as a subject in its own right but is rather embedded in the miscellaneous applications.

In the preparation of "O" level and advanced level ("A" level) syllabuses in Uganda by UNEB, the difficulty of some of the statistical concepts which these syllabi contain appears to be under-estimated, with the result that their statistical content is too extensive (UNEB, 2005). Consequently, these syllabi suffer the lack of emphasis on the use of real data collection and analysis by students, which is thus far from the call by UNEB to use sound statistical reasoning (Opolot-Okurut, Opyene-Eluk, \& Mwanamoiza, 2008). Further, the UNEB syllabi for both "O" and "A" levels (UNEB, 2007) make explicit statements on what statistical ideas and techniques ought to be taught in schools but unfortunately, there is no emphasis on the application of these techniques to understand and to interpret data in real-life situations. Learners commonly attempt questions in statistics but fail to score highly (UNEB, 2012), making the current status of teaching statistics far from satisfactory. Such reports make one wonder that if UNEB has set out its expectations for the teachers and assumedly teachers are taking up their roles, why then the failure in statistics by the students? According to McDuffie (2004), teachers need to have the knowledge of statistics in order to teach statistics and hence, teacher knowledge is fundamental to quality instruction.

Shulman (1986), outlined seven types of teacher knowledge for successful teaching. These include: "(i) content knowledge; (ii) general pedagogical knowledge; (iii) curriculum knowledge; (iv) pedagogical content knowledge (PCK); (v) knowledge of learners and their characteristics; (vi) knowledge of educational contexts; and (vii) knowledge of educational ends, purposes and values", (p. 8). Hence, he articulated the importance of knowledge to a teacher. Shulman stressed the importance of CK and PK to the teacher. He defined CK as "the amount and organization of knowledge per se in the mind of the teacher" (p. 9). Shulman defined PK as the knowledge of "how to teach" (p. 6), and more solidly later as, "how teachers manage classrooms, organize activities, allocate time and turns, structure assignments, ascribe praise and blame, formulate the levels of their questions, plan lessons, and judge general student understanding" (p. 8).

Shulman (1986) noted that CK and PK were inseparable, stressing that, "mere content knowledge [CK] is 
likely to be as useless pedagogically as content-free skill [i.e. PK]" (p. 8). Hence he proposed "pedagogical content knowledge" (PCK) for which he defined as, "pedagogical knowledge [PK], which goes beyond knowledge of subject matter per se [i.e. CK] to the dimension of subject matter knowledge for teaching [i.e. PK]" (p. 9). While there could be several contributory factors to students' poor performance in statistics in most Ugandan schools, the teachers' PCK may have played a major role. Hence the need for this study to find the relationship between the teachers' levels of PCK and their teaching of statistics. In particular this study sought to find the relationship between the teachers' levels of general knowledge; pedagogical knowledge (PK); and content knowledge (CK) and the teaching of statistics in secondary school in Wakiso district in Uganda.

\section{Review of Related literature}

Recent research on mathematics knowledge for teaching has focused on questions such as how mathematics knowledge is used in teaching. Many researchers (Callingham, Carmichael \& Watson, 2015; Estrella, Olfos \& Mena-Lorca, 2015; Ijeh, 2013; Ijeh \& Onwu, 2012; Ma'rufi, Budayasa \& Juniati, 2018; Rosenkranzer, Horsch, Schuler \& Riess, 2017; Watson \& Callingham, 2013; Widodo, 2017) have examined teachers' knowledge and the roles knowledge plays in shaping teaching practices. For example, Callingham et al. (2015) explored the influence of teachers' PCK on explaining student achievement in statistics. They collected data from 789 students from three Australian states. The students completed three tests and their teachers completed a survey that included items measuring their PCK for teaching statistics. Through multilevel modelling of their data, they indicated that students' outcomes were influenced positively by their teacher's PCK. However, despite Callingham et al. developing valid instruments to measure both student and teacher CK and teachers' PCK, they found linking teachers' knowledge directly to students' learning outcomes elusive.

Estrella et al. (2015) developed a questionnaire on the knowledge of statistics among primary school teachers and their knowledge of how to teach statistics. Their questionnaire focused on teacher awareness of student statistical knowledge and the teaching of statistical content. The questionnaire comprised a total of 14 items and was administered to 85 primary school teachers and their 994 respective students in Chilean schools. Having performed exploratory and confirmatory factor analyses, they found the instrument to be valid and reliable. Ijeh (2013) studied the mathematics teachers' PCK for teaching statistics. He collected data from four mathematics teachers in a South African university through a conceptual knowledge exercise, concept mapping, lesson observation, questionnaire, video recording, teachers' written reports and document analysis. Having identified themes and patterns basing on iterative coding and categorisation of responses and observations, he found that mathematics teachers possessed topic-specific subject matter CK and conceptual knowledge to teach statistics in school mathematics.

Ijeh and Onwu (2012) studied how mathematics teachers applied PCK to identify and deal with learners' conceptions in statistics. They collected data about learners' conceptions (preconceptions and misconceptions) from four teachers in a South African university by means of lesson observation, teacher interview, questionnaires, video recordings, teachers' written reports and document analysis. Through coding and categorisation, they found that mathematics teachers deal with learners' conceptions in statistics by applying topic-specific instructional skills and strategies; using learners' responses to oral questioning; setting pre-activities; the checking and marking of learners' class work, homework and assignments; and analysing learners' responses to class work, homework and post-teaching discussions.

Ma'rufi et al. (2018) aimed at describing the profile of high school teachers' PCK in learning mathematics from the perspective of teaching experience. The focus of their research was how the novice teachers' PCK dealt with the knowledge of student. They defined the knowledge of student as a teacher's knowledge about the students' conception and misconception on limit of function material and the teacher's ability to cope with students' difficulties, mistakes, and misconceptions. They collected data from two high school mathematics teachers who had different teaching experiences through interview and observation. These two teachers were from the same high school in Indonesia. Having analysed their data qualitatively, Ma'rufi et al. showed that novice teachers' ability in analysing the cause of students' difficulties, mistakes, and misconceptions was limited. Hence, novice teachers tended to overcome the students' difficulties, mistakes, and misconceptions by re-explaining the procedures of question completion which was not understood by the students.

Rosenkranzer et al. (2017) studied the effects of three different interventions namely technical course, didactic course and mixed course in student teachers' PCK for teaching systems thinking. Using a mixed methods approach, they collected data using a questionnaire with open-ended items and a quasi-experiment from 108 student teachers at the Universities of Education in Freiburg and Ludwigsburg in Germany. They used descriptive statistics and a coding scheme to show that student teachers' PCK for teaching systems thinking can be promoted in teacher education. In particular, they established that a technically oriented course without didactical aspects is less effective in fostering student teachers' PCK for teaching systems thinking.

Watson and Callingham (2013) considered the responses of 26 teachers from three Australian states to items exploring their PCK about the concept of average. The items explored teachers' knowledge of average, their 
planning of a unit on average, and their understanding of students as learners in devising remediation for two student responses to a problem. They used rubrics for assessing the responses and their results indicated a wide range of performances and a wide range of ability in relation to a hierarchical statistical PCK scale. Widodo (2017) reported on findings from a three-year project in Indonesia that investigated teacher pedagogical content knowledge and students' reasoning and wellbeing. Although he did not specify in his article what the study sample comprised and how it was selected and how he collected or analysed data, he indicated that students' reasoning was relatively low and that they could not construct highly coherent arguments. He further showed that teachers needed intensive and continuous support in improving their PCK.

All the eight reviewed studies have been on measuring how much PCK teachers possessed (Ijeh, 2013; Watson \& Callingham, 2013), the development of teachers' PCK (Rosenkranzer et al., 2017), how teachers applied their PCK (Ijeh \& Onwu, 2012; Ma'rufi et al., 2018; Widodo, 2017), instruments to measure PCK (Estrella et al., 2015) and how PCK influence students' achievement (Callingham et al., 2015). None of the studies has looked at the relationship of teachers' PCK and their teaching of statistics, a gap this study wishes to fill.

\section{Method}

\subsection{Instruments}

Self-Administered Questionnaire (SAQ). The SAQ had three constructs on PCK. PCK was conceptualized as the teachers' levels of general knowledge (6 items), pedagogical knowledge (6 items) and content knowledge (6 items). On the other hand, the instrument had 22 items on the teachers' teaching of statistics. The 40 items were scaled on a five-point Likert scale ranging from 1 (Strongly disagree) to 5 (Strongly agree). The reliability of the SAQ on multi-item variables was established through pilot testing.

Classroom Observation Guide. The classroom observation guide had three constructs to observe namely introduction skills ( 3 items), process skills (10 items) and communication skills (5 items) pertaining to teachers' general, pedagogical and content knowledge. Each of the 20 teachers selected was observed between 70-90 minutes, depending on the duration of the lesson. The number of teachers who possessed each of the 18 skills was counted.

Interview Guide. The interview guide had eight questions to probe into the teachers' PCK and their teaching of statistics. The interviews lasted between 45-60 minutes with each of the 10 teachers that were selected.

Document Analysis Guide. The document analysis guide had three questions that were used to analyse a teacher's scheme of work, lesson plan and lesson notes that the teacher carried to class. In particular, the study was interested in finding out the teachers' aims of teaching statistics presented to the students, the methods of teaching they indicated to use, examples they intended to use in class, and the teaching materials they prepared to use in class.

\subsection{Sample}

Schools. The sample consisted of ten secondary schools. In order to maintain confidentiality, the schools were given pseudonyms namely Aluhu, Boho, Chandru, Drula, Elonda, Fetha, Glenora, Hondalu, Ituli, and Jameyi. According to Kizza (2018), UNEB listed the best ten performing districts in Uganda's Advanced Certificate of Education (UACE) and in each of the districts, it listed the best 20 schools. Wakiso was the biggest district of the listed districts and from its 20 listed schools, came the sample of the ten schools. These schools were both urban (6 schools) and rural (4 schools); and private (4 schools) and government (6 schools). The sampled schools had sufficient teaching materials (including computers and calculators), enough textbooks; enough teachers and comparatively similar performance in order to cater for extraneous variables.

Teachers. Out of each selected school, six statistics teachers were selected and thus, the participants in this study were 60 secondary mathematics [statistics] teachers. There were four times as many males ( $80 \%)$ as females $(20 \%)$ who teach statistics in secondary schools. About 62 percent of the teachers had a teaching experience of more than 11 years and the majority $(78.3 \%$ ) had only a bachelors' degree. Meanwhile, the teachers who majored $(70 \%)$ in mathematics at higher institutions were more than twice as many as those who offered (30\%) mathematics as a minor subject. The majority of the mathematics majors had Economics as their second teaching subject. Almost 77 percent of the teachers were married. None of the teachers had a degree in statistics or a degree in teaching statistics but rather all of them had one or two course units in statistics at the University. Also, none of the teachers had received in-service training in teaching statistics.

\subsection{Data Analysis}

The average index of the content validity of the SAQ was found to be 0.78 which is an acceptable level (Amin, 2005). To achieve the three objectives of this study, the items of teachers' general knowledge, pedagogical knowledge, content knowledge and the teaching of statistics were described in terms of their means and their overall rating based on the five-point Likert scale. The relationships between general, pedagogical and content knowledge and the teaching of statistics were found using Pearson's Linear Correlation Coefficient. The data from 
lesson observations, interviews and document analyses were categorised and scored and also reported as narratives.

\section{Findings}

4.1. Teachers' General Knowledge and Teaching Statistics

The first objective of this study was to find the relationship between the teachers' levels of general knowledge and teaching statistics in secondary schools in Wakiso district. Tables 1 and 2 give the means and the ratings of the items of teachers' levels of general knowledge and the teaching of statistics respectively. These items were answered on a five-point Likert scale ranging from 1 (strongly disagree) to 5 (strongly agree). According to Tables 1 and 2, the teachers' general knowledge and teaching statistics had overall means of 3.36 and 3.09 respectively. These values indicate that teachers neither disagreed nor agreed to items rating their general knowledge and teaching statistics. Table 3 shows that no teacher carried other information sources to the classroom apart from textbooks and that a few (25\%) teachers gave instructions in their lessons. Still, a few $(35 \%)$ teachers introduced the lessons according to their lesson plans. Table 4 reveals that majority $(65.0 \%)$ of the teachers whose documents were analysed carried their own lesson note books to class and a few (35\%) teachers conducted their lessons following their lesson plans. Only 10 percent of the teachers had schemes of work.

Table 1: Teachers' General Knowledge of Teaching Statistics

\begin{tabular}{|c|c|c|}
\hline Item & Mean & Rating \\
\hline $\begin{array}{l}\text { I hold productive conversations about mathematical ideas with my } \\
\text { students }\end{array}$ & 2.56 & Neither disagree nor agree \\
\hline I evaluate students' ideas & 2.85 & Neither disagree nor agree \\
\hline $\begin{array}{l}\text { I interpret students' explanations to the whole class while I am } \\
\text { teaching }\end{array}$ & 2.97 & Neither disagree nor agree \\
\hline I know and use definitions of terms and use them correctly & 3.73 & Agree \\
\hline I use clear explanations about concepts & 4.00 & Agree \\
\hline $\begin{array}{l}\text { I consider key principles and ideas that underlie statistics while } \\
\text { teaching }\end{array}$ & 4.02 & Agree \\
\hline Overall & 3.36 & Neither disagree nor agree \\
\hline
\end{tabular}

Table 2: Teachers' views on teaching statistics

\begin{tabular}{lll}
\hline Item & Mean & Rating \\
\hline I read and explain the text book & 4.23 & Agree \\
Statistics does not need practical work & 3.80 & Agree \\
I need to cover as many problems as possible in past examinations & 4.18 & Agree \\
I dictate notes to the class since students are mature enough & 1.55 & Disagree \\
I use the lecture method to teach statistics & 4.00 & Agree \\
I sometimes use question and answer approach while teaching & 4.00 & Agree \\
statistics towards examinations & & \\
Sometimes I leave the students to research and collect their own data & 2.62 & Neither disagree nor agree \\
I prepare for the lesson before I go to class & 4.00 & Agree \\
I endeavour to return students' written assignments in time. & 4.00 & Agree \\
I explain all the difficult concepts in statistics & 1.33 & Strongly Disagree \\
I criticize students for their academic mistakes & 2.57 & Neither disagree nor agree \\
I accept my students' suggestions & 2.48 & Neither disagree nor agree \\
I take remedial classes for the weak students & 1.43 & Strongly Disagree \\
I act as a guide to students' problems & 2.53 & Neither disagree nor agree \\
I make sure that I give clear instructions to students during practical & 4.00 & Agree \\
and class work & & \\
I encourage myself to be positive to my students during statistics & 4.00 & Agree \\
lessons & & \\
I reward for student academic performance & 1.38 & Strongly disagree \\
I try to communicate to students in a language they understand & 4.00 & Agree \\
I take interest in personal problems of my students & 2.65 & Neither disagree nor agree \\
I encourage my students during my lessons & 3.73 & Agree \\
I punish weak students for being lazy & 2.48 & Neither disagree nor agree \\
I have open conversations with my students & 2.97 & Neither disagree nor agree \\
Overall & 3.09 & Neither disagree nor agree \\
\hline
\end{tabular}


Table 3: Teachers' Scores during Classroom Observations in Introduction Skills Introduction Skills

Percentage scores

(Number of Total Scores)

$\begin{array}{lr}\text { Lesson plan } & 35.0(07) \\ \text { Instructions given } & 25.0(05) \\ \text { Information sources apart from textbooks } & 00.0(00)\end{array}$

Table 4: Teachers' Scores on Document Analysis

$\begin{array}{rr}\text { Documents } & \text { Percentage scores } \\ \text { (Number of Participants with th }\end{array}$

\begin{tabular}{ll}
\hline Scheme of Work & $10.0(02)$ \\
Lesson Plan & $35.0(07)$ \\
Lesson Notes & $65.0(13)$
\end{tabular}

\begin{abstract}
Classroom observations revealed that the aims of teaching particular topics presented in the teachers' documents centred mostly on the students being able to solve as many problems as possible and applying routine statistical formulae. Interviews revealed that the teachers had to rush through the syllabus in order to complete it before the final examinations. The rush left them with no opportunity to explain the nature of statistics and the aims of teaching it. They rather insisted on formulae and calculations such that students could be able to pass their final examinations. Concerning the nature of teaching statistics, the teachers indicated that teaching statistics basically emphasized definitions and calculations. Pearson's Correlation Coefficient, $r=0.130$ between the scores on teachers' levels of general knowledge and teaching statistics and a p-value of 0.320 indicated that at the 0.05 significance level, the relationship between the two variables was not statistically significant, thus, there was no relationship between the teachers' levels of general knowledge and teaching statistics.
\end{abstract}

\title{
4.2. Teachers' Pedagogical Knowledge and Teaching Statistics
}

The second objective of this study was to find the relationship between the teachers' levels of pedagogical knowledge and teaching statistics in secondary schools in Wakiso district. Tables 5, 6a and 6b give the means and the ratings of the items of teachers' levels of pedagogical knowledge and classroom observations respectively. The items in Table 5 were answered on a five-point Likert scale ranging from 1 (strongly disagree) to 5 (strongly agree). According to Table 5, the overall mean of teachers' pedagogical knowledge (PK) was 3.31 indicating that teachers neither disagreed nor agreed to the items rating their PK. Table 6a shows that while all teachers did not use displays during teaching statistics, 90 percent of them used lecture methods. While 50 percent of the teachers used many examples on a particular concept while teaching and 45 percent of them used a meaningful statistic language to the students, only five percent of the teachers modified problems to make them either harder or easier to challenge students. Table $6 \mathrm{~b}$ shows that only a few $(5 \%)$ teachers listened to, as well as interacted with the students and all of them gave notes to the students. Because only 10 percent of the teachers gave time to the students, very few $(15 \%)$ students were able to ask questions during the lessons.

Table 5: Teachers' Pedagogical Knowledge of Teaching Statistics

\begin{tabular}{lll}
\hline Item & Mean & Rating \\
\hline $\begin{array}{l}\text { I modify problems to be easier or harder to test the students } \\
\text { understanding }\end{array}$ & 2.67 & Neither disagree nor agree \\
$\begin{array}{l}\text { I use a mathematical language which is easier in a variety of ways } \\
\text { for my students and yet mathematically correct }\end{array}$ & 3.37 & Neither disagree nor agree \\
$\begin{array}{l}\text { I recognize different ways to solve the same problem } \\
\text { I ask my students to make mathematical justification, conjectures }\end{array}$ & 3.47 & Agree \\
$\begin{array}{l}\text { and look for patterns of their answers and reasoning } \\
\text { I choose useful examples while teaching }\end{array}$ & $\begin{array}{l}\text { Disagree } \\
\text { I select appropriate representations while teaching }\end{array}$ & $\begin{array}{l}\text { Agree } \\
\text { Overall }\end{array}$ \\
\hline
\end{tabular}

Table 6a: Teachers' Scores during Classroom Observations in Process Skills

\begin{tabular}{lc}
\hline Process Skills & Percentage Scores (Number of Scores) \\
\hline Displays (e.g. charts, data) involved / representations & $00.0(00)$ \\
Examples used & $50.0(10)$ \\
Language used. Is it meaningful to students? & $45.0(09)$ \\
Modification of problems & $05.0(01)$ \\
Teaching methods used, lecture or inquiry? & $90.0(18)$ \\
\hline
\end{tabular}


Table 6b: Teachers' Scores during Classroom Observations in Communication Skills

\section{Communication Skills}

Percentage Scores

(Number of Total Scores)

\footnotetext{
Taking of notes

$100.0(20)$

$05.0(01)$

How often the teacher listens to students

$10.0(20)$

The time the teacher gives to students to ask questions

$05.0(01)$

Interaction between teacher and students

$15.0(03)$

Ability of students to ask questions

Classroom observations showed that teaching was teacher-controlled and basically theoretical. Too much emphasis was placed on the application of statistical techniques rather than on discussion of the results, examination of the data and on the inferences which should be drawn in the light of the context of the data used. Teachers solved many problems picked from textbooks and past paper examinations with slight description and passed on a few questions to the students moreover, textbooks as were available concentrated on theory rather than practice. The teachers emphasized the presentation of correct formulae and correct answers, drawing correct graphs and drawing simple conclusions. Meanwhile, statistics concepts were generally not related to real life experiences. Document analysis revealed some lessons were either far behind or far ahead of what the teachers had planned. Some lesson plans' dates, classes and/or streams and number of students did not tally with the actual lessons.

During actual teaching, discussions were rare. Interviews revealed that according to the teachers, discussions consume a lot of time yet they have to catch up with the wide syllabus and hence, engage with discussions towards examination periods. The teachers also indicated that they gauged their students' understanding of statistical concepts through the marks that they obtained from assignments, tests and examinations. However, they would not know if the given assignments were copied from fellow students or even, if the high scores from examinations were a result of cramming formulae. Almost all interview responses were centred on students' passing of examinations. Pearson's linear correlation coefficient, $r=0.004$ between scores on levels of pedagogical knowledge (PK) and teaching statistics and a p-value of 0.978 indicated that at the 0.05 significance level, the relationship between the two variables was not statistically significant, thus, there was no relationship between teachers' PK and teaching statistics.
}

\subsection{Teachers' Content Knowledge and Teaching Statistics}

The third objective of this study was to find the relationship between the teachers' levels of content knowledge and teaching statistics in secondary schools in Wakiso district. Tables 7 and 8 give the means and the ratings of the items of teachers' levels of content knowledge and classroom observation respectively. The items in Table 7 were answered on a five-point Likert scale ranging from 1 (strongly disagree) to 5 (strongly agree). According to Table 7, the overall mean of the teachers' content knowledge (CK) was 2.64 which indicated that teachers neither disagreed nor agreed to the items rating their CK. Table 8 shows that all teachers did not evaluate students' ideas and only 10 percent of them gave clear explanations to the students. While only 15 percent of the teachers gave clear definitions of statistical concepts and did not use them appropriately, 30 percent gave the sequence of events while they taught. Only 25 percent of the teachers gave details of the topic at hand. Table 7: Teachers' Views on Content Knowledge of Teaching Statistics

\begin{tabular}{lll}
\hline Items & Mean & Rating \\
\hline I explain goals and mathematical ideas to students & 2.32 & Neither disagree nor agree \\
I emphasize appropriate levels of accuracy & 2.43 & Neither disagree nor agree \\
I recognize wrong answers, spot the method used to get a wrong & 2.45 & Neither disagree nor agree \\
answer and recognize when a right answer is a result of faulty & & \\
thinking & & \\
I find out what my students did wrong when I give exercises & 2.50 & Neither disagree nor agree \\
I build correspondences between models and procedures & 3.02 & Neither disagree nor agree \\
I am aware and use a variety of interpretation of figures and data & 3.10 & Neither disagree nor agree \\
Overall & 2.64 & Neither disagree nor agree \\
\hline
\end{tabular}

Table 8: Teachers' Scores in Classroom Observations in Process Skills

\begin{tabular}{lc} 
Process Skills & $\begin{array}{c}\text { Percentage scores } \\
\text { (Number of Scores) }\end{array}$ \\
\hline Definitions given and how they are used & $15.0(03)$ \\
Details of topic given & $25.0(05)$ \\
Sequence of events & $30.0(06)$ \\
Explanations given. Are they clear? & $10.0(02)$ \\
Evaluation of students' ideas & $00.0(00)$ \\
\hline
\end{tabular}


The teachers' documents did not reveal greater emphasis to the selection and proper use of data representation and analysis. An examination of explanations, examples and analogies that the teachers used to guide students' development of an understanding of statistics indicated that most teachers' actions largely stemmed from an understanding based on having been taught in particular ways. Interviews revealed that the teachers hardly tried data collection with themselves and the students as well. They only used data from textbooks. Most teachers lacked the knowledge of how statistical concepts and topics spiralled and what topics students found either easy or difficult. They also did not recognise the importance of helping students orient themselves to data, thus, a lack of demonstration of the knowledge of students' likely levels of understanding. Pearson's Correlation Coefficient, $\mathrm{r}=$ 0.084 between the scores on the levels of content knowledge (CK) and teaching statistics and a p-value of 0.522 indicated that at the 0.05 significance level, the relationship between the two variables was not statistically significant, thus, there was no relationship between the teachers' CK and teaching statistics.

\section{Discussion}

The first objective of this study was to find the relationship between the teachers' general knowledge and teaching statistics. According to the overall mean (Table 1), teachers neither disagreed nor agreed to items rating their general knowledge of teaching statistics. This implied that teachers were not sure of their general knowledge of teaching statistics. The teachers' rating was not surprising as interviews, document analysis and classroom observations revealed that the teachers' aims of teaching particular topics that they presented were majorly centred on the students being able to solve as many problems as possible and applying statistical formulae. In essence, this provides a poor foundation for the students for developing analytical and statistical literacy skills. They will not have the capacity to make sense of data in context. Pearson's linear correlation coefficient revealed that there was no relationship between the teachers' general knowledge and teaching statistics. This finding is in consonance with Widodo (2017) who having attempted to support teachers to conduct lessons that facilitated students' reasoning, found that teachers' general knowledge was lacking and needed intensive and continuous support to enhance reasoning among the students. Further, this finding could be lent to the teachers' inadequate planning for the statistics lessons, as very few of them had lesson plans. This was evident during classroom observation. There was no preparation for teaching and lessons development was generally flat as there was no introduction of the lessons but rather emphasis on formulae and computations, an indicator that the teachers do not understand what is expected of statistics.

The second objective of this study was to find the relationship between the teachers' pedagogical knowledge and the teaching of statistics. Table 5 shows that corresponding to the overall mean, teachers neither disagreed nor agreed to the items rating their pedagogical knowledge (PK) of teaching statistics. This means that the teachers still, were not confident about their PK. The lack of PK by teachers limits and affects the teaching of statistics. The teachers expressed a predominant use of teacher-controlled teaching, where students have little interruptions and choices in reasoning, organizing or displaying results. One possible explanation of this could be pressures from the UNEB examinations policy that require teachers to complete the syllabus before the students' final examinations. This makes teachers to rush through the syllabus without emphasis on understanding. Another explanation is that there are no pre-service training programmes to offer statistics teaching methods and no efforts have been put in towards in-service training for the teachers already in active teaching. Pearson's linear correlation coefficient revealed that there was no relationship between the teachers' pedagogical knowledge and teaching statistics. This finding supports what Opolot-Okurut, et al (2008) found to the effect that statistics is taught by teachers who have pedagogical knowledge to teach mathematics but hardly had an opportunity to develop sound knowledge on the principles and concepts underlying good practices of teaching statistics. This means that teachers are unable to deal with learners' conceptions in statistics. They do not know how to interpret students' explanations and cannot tell if the representations and examples they select are useful to the students because they are already laid down, step-by-step, in the textbooks and only need shallow explanations. Yet, according to Ijeh and Onwu (2013), mathematics teachers deal with learners' conceptions in statistics by applying topic-specific instructional skills and strategies.

The third objective of this study was to find the relationship between the teachers' content knowledge and teaching statistics. The overall mean according to Table 5 revealed that teachers neither disagreed nor agreed to items rating their content knowledge $(\mathrm{CK})$ of teaching statistics. This meant that teachers were not sure of the statistics content yet, high quality teaching requires that teachers have a deep knowledge of content. Although in any teaching and learning process, teachers must possess considerable knowledge on the content to be taught, design appropriate approaches and plan for effective activities, this was not the case in this study. Document analysis revealed that key concepts were not articulated but instead there was a smattering of statistical terms and formulae. An examination of the clarity and explicitness with which the concepts to be taught were expressed in the lesson plans, the kinds of activities planned, and the teachers' lack of acknowledgement of student understanding all revealed the teachers' lack of content knowledge. Pearson's linear correlation coefficient revealed that there was no relationship between the teachers' content knowledge and teaching statistics. This 
finding is in agreement with Callingham, Carmichael and Watson (2015). Despite their development of valid instruments to measure both student and teacher content knowledge and teachers' PCK, they found linking teachers' knowledge directly to students' learning outcomes elusive yet according to them, students' outcomes are influenced positively by their teacher's PCK. In a nutshell, the teachers' understanding of the content was not found to be good enough and therefore there was no quality teaching that was reflected during actual teaching. This could be explained by the fact that the content to be covered by the teachers is laid down by UNEB without specific details but rather outlines. As a result, the teachers only cover, from the recommended textbooks and the outlined topics without the emphasis on details of the topics. Further, while the curricula provides an overview of what students should be taught, they do not address the issue of what knowledge is needed by the teachers of these students.

\section{Conclusion and Recommendations}

The study attempted to establish the relationship between teachers' pedagogical content knowledge and the teaching of statistics in secondary schools in Wakiso district. Using Pearson's linear correlation coefficient, it was established that there was no relationship between teachers' PCK and the teaching of statistics. This means that teachers' lack of pedagogical knowledge limits and affects the teaching of statistics in most schools. Also, teachers' lack of planning could be a reason. Unless teachers address these issues and are monitored, the outcry of poor performance shall remain an anthem in the country. The study however, had limitations. For example, the study was applied to only Wakiso district, which is one out of 119 districts in the country. The sample size could have been bigger as well. The teaching of statistics could also have other explanatory variables than PCK that are suggested by other frameworks. The sample of the study was small and not selected to be representative of the large population of secondary school teachers in the country. It was recommended that the Ministry of Education and Sports, National Curriculum Development Centre and Uganda National Examinations Board should identify the training necessary to equip teachers with pedagogical content knowledge to teach statistics effectively, revising the curriculum and emphasizing a practical approach in teaching statistics in teacher preparation programmes, designing modules for pre-service and in-service mathematics teachers in order to improve their PCK in teaching statistics and also emphasize practical use of real life data by providing guidelines and manuals to all secondary schools.

\section{References}

Amin, M. (2005). Data Analysis for Social Sciences. Makerere: Makerere University Printery.

Callingham, R., Carmichael, C., \& Watson, J. M. (2016). Explaining student achievement: The influence of teachers' pedagogical content knowledge in statistics. International Journal of Science and Mathematics Education, 14, 1339-1357.

Estrella, S., Olfos, R., \& Mena-Lorca, A. (2015). Pedagogical content knowledge of statistics among primary school teachers. Education Pesqui Sao Paulo, 41(2), 477-492.

Ijeh, S. B. (2013). Pedagogical content knowledge (PCK) development in statistics teaching: What content knowledge does mathematics teachers have and demonstrate during classroom practice? Mediterranean Journal of Social Sciences, 4(14), 191-200.

Ijeh, S. B., \& Onwu, G. O. M (2012). Using pedagogical content knowledge (PCK) by competent mathematics teachers to deal with learners' conceptions in statistics teaching. International Journal of Education Science, $5(4), 612-624$.

Ma'rufi, I., Budayasa, K., \& Juniati, D. (2018). Pedagogical content knowledge: teachers' knowledge of students in learning mathematics on limit of function subject. Journal of Physics: Conference Series, 954, 1-8.

McDuffie, A. R. (2004). Mathematics teaching as a deliberate practice: An investigation of elementary preservice teachers' reflective thinking during student learning. Journal of Mathematics Teacher Education, 7, 33-61. Netherlands: Kluwer Academic Publishers.

Ministry of Education, Science, Technology and Sports (MoESTS) (2008). Improving the Teaching Mathematics and Science. Ministry of Education and Sports: Kampala.

Opolot-Okurut, C., Opyene-Eluk, P., \& Mwanamoiza, M. (2008). The current teaching of statistics in Ugandan schools. In C. Batanero, G. Burrill, C. Reading \& A. Rossman (Eds.), Joint ICMI/IASE Study: Teaching Statistics in School Mathematics. Challenges for Teaching and Teacher Education. Proceedings of the ICMI Study 18 and 2008 IASE Round Table Conference. Monterrey, Mexico.

Rosenkranzer, F., Horsch, C., Schuler, S., \& Riess, W. (2017). Student teachers' pedagogical content knowledge for teaching systems thinking: Effects of different interventions. International Journal of Science Education, 39(14), 1932-1951.

Shulman, L. S. (1986). Those who understand: Knowledge growth in teaching. Educational Researcher, 15(2), 4-14.

Uganda National Examinations Board (2005). Uganda Certificate of Education: Regulations and Syllabuses, 
2005-2010. Kampala: Author

Uganda National Examinations Board (2006). Uganda Certificate of Education: Regulations and Syllabuses, 2006-2011. Kampala: Author

Uganda National Examinations Board (2012). Uganda Advanced Certificate of Education: Regulations and Syllabuses, 2012-2017. Kampala: Author.

Uganda National Examinations Board (2007). Uganda Certificate of Education: Regulations and Syllabuses, 2007-2012. Kampala: Author

Watson, J. M., \& Callingham, R. (2013). PCK and average. In V. Steinle, L. Ball \& C. Bardini Mathematics Education: Yesterday, Today and Tomorrow. Proceedings of the $36^{\text {th }}$ Annual Conference of the Mathematics Education Research Group of Australasia. Melbourne, VIC: MERGA.

Widodo, A. (2017). Teacher pedagogical content knowledge (PCK) and students' reasoning and wellbeing. Journal of Physics: Conf. Series, 812, 1-7. http://doi.org/10.1088/1742-6596/812/1/012119 